\title{
Cross-cultural Research, Evolutionary Psychology, and Racialism: Problems and Prospects
}

\author{
John P. Jackson, fr. $^{\S}$
}

\begin{abstract}
Philosophers defending evolutionary/cognitive accounts of racialism argue that cross-cultural psychological research has discovered similar patterns of racial reasoning around the globe. Such research, they hold, simultaneously supports the existence of an underlying cognitive mechanism for essentialist thinking while undercutting social constructionist accounts of racialism. I argue that they are mistaken for two reasons. First, evolutionary/cognitive researchers are unfamiliar with constructionist accounts of global racialism which explain similarities and differences in racialism. Second, evolutionary/cognitive accounts that make cross-cultural claims shoulder probative obligations for showing the independence of the cultures being compared, and these obligations have not been met. I argue that further evolutionary/cognitive research on racialism must account for constructionist models of global racialism while meeting the argumentative obligations of cross-cultural research.
\end{abstract}

\section{KEYWORDS \\ Evolutionary Psychology $\bullet$ Racialism $\bullet$ Anthropology $\bullet$ Cross-cultural Research $\bullet$ Research Groups}

\section{Introduction}

This essay is a defense of the social construction of racialism. I follow a standard definition of "racialism" which is the belief that "there are heritable characteristics, possessed by members of our species, that allow us to divide them into a small set of races, in such a way that all the members of these races share certain traits and tendencies with each other that they do not share with other members of any other race" (Appiah 1990, 4-5). ${ }^{1}$ In particular I want to defend the "radical" social-constructive thesis that holds "the concept of race is exclusively the product of historical and cultural causes. It claims that humans do not tend to classify people into races when groups with different phenotypes meet, save for particular historical circumstances" (Machery and Faucher 2010b, 1015; see also Mallon 2010, 272). The quoted position is the consensus view among historians, sociologists, anthropologists, and other social scientists who study racialism but has recently been criticized by philosophical defenders of cognitive/evolutionary psychological (GEP) approaches to racialism. Drawing on developmental studies as well as historical and contemporary cross-cultural research, CEP philosophers point to similarities of racialism across time and space. They hold that social constructionist (SG) approaches to racialism cannot explain these similarities. I hold that $\mathrm{SC}$ approaches do explain these similarities and that such similarities actually pose a significant challenge to the proposed GEP research program on racialism.

There are several competing cognitive mechanisms proposed in the CEP literature as to the exact nature of the module that causes racialism (for a summary of these competing approaches see Machery and Faucher 2005b, 1016-1020). What all these accounts share is the claim that "racial cognition is the byproduct of a mental mechanism that evolved for some other purpose" (Hochman 2013, 995). For my

$\S$ Roy R. Charles Center for Academic Excellence, College of William and Mary, PO Box 8795, Williamsburg, VA 23187-8795 USA ¿-mail: jpjackson01@wm.edu 
purposes, the exact nature of this proposed mechanism is not as important as how the cross-cultural evidence is rallied to support its existence by CEP researchers. The CEP research program on racialism calls upon three lines of evidence: first, developmental studies of children which seem to indicate that even infants can distinguish between races (e.g. Hirschfeld 2012); second, a historical argument that identifies racialism in antiquity or non-Western cultures before contact with Europeans (e.g. Mallon 2010); third, a cross-cultural argument that holds that there is a similarity in racialism across the globe because "the social constructionist approach does not explain why races are cross-culturally thought of as biological kinds" (Machery and Faucher 2005b, 1016), and thus some kind of cognitive module is needed to explain such similarities. My focus in this paper is only on the third line of evidence. Thus, evidence such as that provided by Kurzban, Tooby, and Cosmides (2001) is not part of my critique because their experimental subjects were all University of California, Santa Barbara undergraduates. Only if such a study were replicated elsewhere and an argument offered that claimed that such a "cross-cultural" finding was evidence for a cognitive mechanism would my argument here apply. On the other hand, Hirschfeld's enrollment of a "small flood of studies" across the globe that indicate that "infants are hardly blind to race" (Hirschfeld 2012, 18) is critiqued here, not because I am interested in the fact that he is calling upon developmental studies per se but because he is enrolling such studies in a cross-cultural manner. I will expand on my reasons for this in Section 3 below, but, in short, I am critiquing CEP researchers' employment of cross-cultural data regardless of the specifics of their proposed cognitive mechanisms.

I would like to specify two ways in which the position I will defend can be considered constructionist. First, social constructionism, Ian Hacking reminds us, tends toward nominalism. "Constructionists," he writes, "tend to maintain that classifications are not determined by how the world is, but are convenient ways in which to represent it. They maintain that the world does not come quietly wrapped up in facts. Facts are the consequences of ways in which we represent the world" (Hacking 1999, 33). A key part of my argument defending radical social construction hinges on this very point: we must be nominalists about "different" cultures. If we choose to name cultures we should always bear in mind that the names we give to them are products of our own invention and do not inhere in the actual structure of the (human) world. The position I defend has long been articulated in anthropology. In 1936, Robert Lowie argued:

A specific culture is an abstraction, an arbitrarily selected fragment. Social tradition in some measure varies from family to family. Shall we, then, study a single Hopi family, the Hopi village of Walpi or the seven Hopi villages, the Pueblo area of North America, if not the New World as contrasted with the Old? There is only one cultural reality that is not artificial, to wit: the culture of all humanity at all periods and in all places. (Lowie 1936, 305)

Second, I will defend a broad sense of "diffusionism" which holds that "it is not fundamental essential characteristics of human beings that explain history but the accidents of who we are with and have been with.... Talk of 'construction' in the social sciences is a reformulation of diffusionism" (Bloch 2005, 7-8).2 Again, my position is neither new nor radical. At the end of the nineteenth century Franz Boas argued against environmental determinism of culture by claiming that "Not one observed fact can be brought forward in support of this hypothesis [of environmental determinism] which cannot be much better explained by the well known facts of diffusion of culture; for archeology as well as ethnography teach us that intercourse between neighboring tribes has always existed and has extended over enormous areas" (Boas 1896, 906).

I will show that the global similarities in racialism are better explained by constructionist models of diffusion than by CEP models of an underlying cognitive mechanism. I proceed as follows: First, I outline the CEP argument that global, cross-cultural similarities in racialism are evidence for the existence of an underlying cognitive mechanism that explains such similarities. Second, I outline the underlying reasoning process that warrants CEP philosophers' claim that they explain this cross-cultural similarity. Additionally, I show how they attempt to assign probative obligations to their intellectual opponents that they themselves should be assuming. Third, I briefly review SC models of diffusion, interaction, and relations of racial thinking in modernity. I show that these models explain the very similarities that CEP researchers claim to have found. Fourth, I outline what is necessary for CEP to sustain claims of cross-cultural findings that would actually support CEP's case for an innate, domain-specific, and species-typical mechanism that supports lineage-essentialist reasoning about human groups. I argue that they have failed to produce such evidence and outline what is entailed by an attempt to do so. 


\section{GEP and the Gognitive Mechanism Underlying Racialism}

Philosophers sympathetic to the evolutionary cognitive approach to racialism have argued that their approach to racialism is a needed supplement to social constructionist accounts of racialism because of the existence of similarities in racialism among unrelated cultures. According to GEP philosophers, psychological research has given us evidence that people generally hold beliefs that

reflect a kind of intuitive essentialism: racial properties are viewed as stable (racial properties do not change during one's lifetime), intrinsic (racial properties are thought to be caused by one's inner nature), innate (the development of racial properties does not depend much on one's rearing environment), and inherited (parents transmit their racial properties to their children). (Kelly, Machery, Mallon 2010, 443)

CEP philosophers further argue that "racial essentialism is a product of an innate, domain-specific, and species-typical mechanism" (Mallon 2013, 86). The mechanism is not designed specifically to classify people by race. Rather, racialism is a product of a specific cognitive module selected for some other social cognitive function (Kelly, Machery, and Mallon 2010, 440).

My particular target in this essay is the cross-cultural evidence they have rallied to support their case. CEP philosophers point to what they claim are similarities of racialism across time and space and conclude that "Evolutionary psychologists hold that people in many cultures and historical epochs have relied on skin color and other bodily features to classify their fellows, and have further believed that such classifications also group together people who share underlying biological commonalities" (Kelly, Machery, and Mallon 2010, 441). This common similarity is explained by cognitive/evolutionary psychology:

The presence of these common themes across different cultures is just what an evolutionary psychologist would expect, since evolutionary psychologists view racial cognition as a by-product of a cognitive system shared by all normally developing humans. In contrast, because socialization accounts cannot explain why these core elements should recur across times and cultures, they are at best incomplete. (Kelly, Machery, and Mallon 2010, 442)

The existence of such cross-cultural patterns in racial thinking points to an explanatory failure of social constructionist (SG) accounts of racialism. Social constructionists, CEP philosophers claim, hold that racial thinking is a recent and local phenomenon, not a global and ancient pattern of thought. CEP philosophers claim that the SC account thus fails in the face of global similarities in racialism: Machery and Faucher maintain that "if something like the concept of race appears in many nonrelated cultures, the radical [SC] thesis is falsified" (Machery and Faucher 2005b, 1015, my emphasis). Thus, "traditional social constructionist explanations are ill-equipped to explain the stability and distinctiveness of racial representations" across the globe or through time (Mallon and Kelley 2010, 512). CEP, however, can explain these things by positing a common cause located long ago, before the human population dispersed over the planet.

Pleas for interdisciplinary cooperation are common among CEP researchers. Machery and Faucher lament that "Social constructionists and evolutionary-minded social scientists avoid interacting with each other. This is detrimental and unjustified" (Machery and Faucher 2005a, 1217). CEP's philosophical defenders often note that the refusal to incorporate psychological explanations of racialism into constructionist accounts displays an anti-psychological bias. Constructionists, they argue, concerned with uncovering the institutional and social foundations of racialism, ignore the possible harmony between their proposed psychological models and the social institutions that concern constructionist accounts (Mallon and Kelly 2012, 522-523). It is certainly true that many in the social sciences are suspicious of "reducing" complex institutional structures to individual cognition (Bonilla-Silva 2014; Duster 2006; Wellman 2007). In the United States this constructionist stance stems at least in part from what SG scholars perceive as an overemphasis on psychological explanations during the nineteen-fifties and nineteen-sixties (for this retreat from psychological and toward structural accounts of racialism see Jackson 1990; Steinberg 1995, 2007). CEP's defenders argue that these concerns are misplaced and that their psychological approach is a useful and necessary supplement to constructionist accounts (Machery and Faucher 2005a, Mallon and Stitch 2000) and that a politically powerful antiracist agenda would be enhanced by recognizing the psychology behind racialism (Kelly, Machery and Mallon 2010; Machery, Faucher and Kelly 2010; Kelly, Faucher and Machery 2010; Mallon and Kelly 2012). 
Yet, constructionists' possibly misplaced fear of imperial cognitivists does not tell the whole story of the failure to integrate CEP with SG accounts of racialism. Machery and Cohen recently defended the evolutionary behavioral sciences against its critics by noting that the critics often limit their criticisms to a handful of well-cited articles. They argue that it is a mistake "to extrapolate from these few alleged paradigmatic articles to a whole field" since research programs seldom follow the strictures laid out in such articles. Moreover, these paradigmatic articles were often dated, having been published at the "end of the 1980s and in the early 1990s" (Machery and Cohen 2012, 186). Unfortunately, CEP researchers fare equally poorly, or perhaps even worse, for engagement with the research program of constructionist researchers. In an article where they bemoan the lack of communication across disciplinary boundaries, Machery and Faucher (2005a) show little knowledge of constructionist theories of race. Of thirty-five sources cited in their article, two articles are made to stand for the entire program of social constructionists. These articles total less than fifty pages of reading and were woefully out of date when they were cited in 2005 (Banton 1970, Omi and Winant 2002 [actually a reprint that was first published in 1986]). Such a pattern of citation is not uncommon in the CEP literature. Not only are the cited SC pieces often dated, but they tend to be the same pieces again and again. An example is their reliance on an essay by Collete Guillaumin (1980) which was first cited by Hirschfeld in 1994 (140). This essay is repeatedly cited in CEP literature as an example of the social constructionist position on racialism (Gelman 2003,14, 299; 2009, 9; Gelman and Hirschfeld 1999, 403; Hirschfeld 1995, 1419; 1996, 22; 2002, 622; Kelly, Machery and Mallon 2010, 442; Mallon 2013, 80; Mallon and Kelly 2012, 513). Guillaumin's essay is a fine piece of work, but it is thirty-five years old and hardly represents recent thinking on the social construction of race. Another example is that the only work of the long career of George Fredrickson used by CEP's philosophical defenders is Racism: A Short History (2002; see Machery and Faucher 2005b, 1012; Mallon 2010, 277; Mallon and Kelly 2012, 513; Mallon 2013,77), which is a short survey of the topic, hardly representative of Fredrickson's complex ideas (1971, 1981, 1995, 1997), and even less representative of the entire research program on the construction of racialism.

Two key claims made by GEP philosophers are completely undocumented. The first is that "the social constructionist approach does not explain the commonalities between the culture-specific concepts of race, e.g., the concepts of race in contemporary North America, in nineteenth-century France, in Germany during the Nazi era, and so on (Machery and Faucher 2005a, 1209-1210; see also Kelly, Faucher and Machery 2010, 441; Mallon 2010, 281). It is telling that these assertions of the failure of SG researchers are just that: assertions. There is no documentation of SC researchers declaring their frustrations in explaining these commonalities. Indeed there is a rich body of scholarly writing that explores the commonalities among the three examples offered by Machery and Faucher (e.g. Kühl 2004; Hecht, 1999, 2000; Malik 1996). As I will show, SC researchers have little problem explaining similarities in racialism all over the globe.

The second common claim that is virtually unsupported in CEP writings is that there is evidence that racialism "is found in representations of human groups independent of the European American tradition of scientific racialism that came to a head in the nineteenth century" (Mallon 2013, 83, my emphasis; see also Mallon 2010, 277-278; Kelly, Machery and Mallon 2010, 441; Machery and Faucher 2005a, 1212-1114; Machery and Faucher 2005b, 1015). Assertions of "independent" or "non-related" cultures are key parts of the GEP argument, because such assertions allow them to find the common cause in the distant past. Significantly, however, there is never an argument advanced to establish that this particular culture is "independent" from that particular culture. The idea "that human groups form distinct empirical entities" is widely seen by SC researchers as one of the "fossils of an earlier age" that has been abandoned in the last three decades (Bloch 2009, 14). By ignoring SC research, CEP researchers repeat methodological errors that have long been recognized in the comparative social sciences. I begin unpacking this argument in the next section.

\section{The Reasoning Behind GEP's Gross-cultural Glaims}

Machery and Faucher (2005a) survey the different CEP approaches to racialism outlining the strength and weakness for Hirschfeld's Human Kind Module, Kurzban, Cosmides, and Tooby's coalitional model, and Gil-White's ethnies model. For each case, Machery and Faucher note how much cross-cultural evidence is cited, and in each case they call for more to be done to substantiate the claims made by the researchers. Comparative research can have many aims, one of which is to establish causal connections (Kocka 2003, 40). CEP researchers use comparisons to establish a causal connection between racialism across the globe to the common environment in which humans evolved. This is an application of Mill's method of agreement: "If two or more instances of the phenomenon under investigation have only one circumstance in common, the circumstance in which alone all the instances agree, is the cause (or effect) of the given phenomenon" (Mill 
1851/2008, 396; see also Ember 1991). In the CEP version, it runs like this: racialism has appeared in what appear to be unrelated cultures. Since the cultures are otherwise unrelated, the cause of the racialism must be the only thing that the cultures share: the environment in the Pleistocene when they evolved the underlying cognitive mechanism for generalization. Thus, pointing to the cross-cultural evidence amassed by CEP researchers, they conclude that it is "best explained by the hypothesis that racial categorization results from a specialized, species-typical cognitive system that, even if it did not initially evolve to deal with racial categorization, has been recruited for this purpose" (Kelly, Machery, and Mallon 2010, 444).

Variations in racial thinking or even its absence entirely in some cultures cannot, in CEP's view, count against the existence of the underlying cognitive mechanism since it can be expressed in a variety of ways or even overridden altogether by culture and learning (Mallon 2013, 86; Kelly, Machery and Mallon 2010, 442). On first glance, this stance would seem to immunize CEP's claims from possible falsification: counterexamples to global racialism can be accounted for in the model, while any examples of global racialism serve as evidence in favor of the existence of the cognitive mechanisms. Rather than searching for counterexamples to the prevalence of racial essentialist thought, I will show how the link between global racialism and a cognitive mechanism that developed during the Pleistocene can be undercut by a demonstration of confounding causal variables that explain global racialism. Simply: if the people living in these cultures came into contact with other people who taught them to think racially, then there is no case that the cause of racial thinking lies in our distant evolutionary past and that therefore CEP researchers have failed to establish their case for the existence of an underlying mechanism. By examining SC models of the diffusion of racial thinking since modernity I will show that GEP has ignored such confounding causal variables in making their case. These SC models demonstrate that the contemporary societies CEP researchers often claim to be "independent" or "unrelated" are embedded in a global, racialist culture.

\section{Against a Billiard Ball World}

In 1982, anthropologist Eric Wolf published Europe and the People without History (1982/2010). In this massive, sprawling book Wolf charged any number of disciplines - history, anthropology, sociology, political science, economics, linguistics. among others - with, as he put it, "turn(ing) names into things" (Wolf 1982, 3). By reifying such concepts as culture, society, nation, etc., these disciplines distorted the reality of human experience. "We create false models of reality," Wolf argued, by treating the world as if it is constituted by "externally distinctive and bounded objects." By so doing "we create a model of the world as a global pool hall in which the entities spin off each other like so many hard and round billiard balls" (Wolf 1982, 6). Wolf argued for replacing our static models of reality with a study of processes: of diffusion, transfer, sharing, conquering and resistance:

The world of humankind constitutes a manifold, a totality of interconnected processes.... Only by understanding these names as bundles of relationships, and by placing them back into the field from which they were abstracted, can we hope to avoid misleading inferences and increase our share of understanding. (Wolf 1982, 3)

Wolf refocused scholarly attention on processes, and what emerged was a picture of the world as a single, unified system. "The more ethnohistory we know, the more clearly 'their' history and 'our' history emerge as part of the same history" (Wolf 1982, 19). Wolf's book was a signal event in reorienting entire fields away from static models of self-contained units and toward dynamic models of processes that connected people with one another (de Munck 2000, 282). Those who studied race and racial thought were especially attuned to the way racial thinking was exported and imported across the globe (Verkuyten and Ter Wal 2000, 4). Since the nineteen eighties, scholars have been busy sketching the "complex processes of diffusion, transfer, adaptation, and transformation of racial ideas in various parts of the world, including their interaction with indigenous traditions" (Berg and Wendt 2011, 2). I will sketch two models to show how the appearance of racial thinking across the globe poses no specific challenges for SC models of racial formation. Some models about the global interconnectivity of the world are, ironically, seen as imperialistic ideologies that read the world through the eyes of European thought (Wacquant 1997, Swyngedouw 2004). In response, more recent formulations of global models of racialism have been careful to track how the commonalities of racialism are tailored by local agents to fit local conditions.

Frank Dikötter argues for an interactive model that avoids the pitfalls of models of diffusion that portray recipients of new ideas as merely passive containers of Western imperialist ideas about racialism. In his view, "the interactive model of interpretation proposed here emphasizes the worldviews constructed by local 
historical agents, analysing the complex cognitive, social and political dimensions behind the indigenization and appropriation of racist belief systems: put briefly, it highlights inculturation where others see acculturation" (Dikötter 2007, 1482). Pointing to his own work on China, Dikötter shows how Western ideas about race found fertile ground in seventeenth-century China onwards because of already existing ideas about patrilineage, increasing militarization which reinforced a social order based on kinship, and other ideas. These ideas, he argues, "were crucial to the emergence of new racial vocabularies, which flourished better in a cultural environment prepared to emphasize real or imagined physical differences between people" (Dikötter 2007, 1484). Such views only intensified in the nineteenth century in the face of demands for equality, which caused a retrenchment of the social order based on an increasingly racist discourse appropriated and modified for local circumstances (Dikötter 2007, 1486-1494). Dikötter's interactionist model does exactly what CEP authors claim SG models cannot do: it explains the similarities between West and East. It does so by focusing on the channels which made possible the transfer of ideas across the globe rather than taking cultures as discrete entities to be compared. By so doing, Dikötter's model explains the similarities in ideas, while simultaneously explaining significant differences in those ideas, by recognizing the agency of local actors who reshaped those ideas to fit local circumstances. CEP writers often look to Dikötter's work to support their argument that racialism in China is evidence for an innate, species-typical cognitive mechanism (Machery and Faucher 2005b, 1015; Mallon 2010, 278; Mallon 2013, 83). They need to come to grips with Dikötter's own explanatory model which actually undercuts their claims by interposing confounding causal variables between the Pleistocene and the flowering of racialism in China.

A similar, though distinct, model has been offered by David Theo Goldberg who criticizes Dikötter's interactionism because it demonstrates interactions "among already constituted discrete national configurations" (Goldberg 2009, 1274). In contrast, Goldberg offers a relational model that centers on the "constitutively relational aspects" of racial conceptions. While granting that the exact arrangement of these aspects are "no doubt deeply local in the exact meanings and resonances they exhibit," he argues that they are "nevertheless almost always tied to extra- and transterritorial conceptions and expressions, those that circulate in wider meaning and practice" (Goldberg 2009, 1273). Embracing this relational view of racialism explains local variations in discourse, because racial ideas are adapted and modified to local needs and power structures. At the same time, however, "racial ideas, meanings, exclusionary and repressive practices in one place are influenced, shaped by and fuel those elsewhere. Racial ideas and arrangements circulate, cross borders, shore up existing or prompt new ones as they move between established political institutions" (Goldberg 2009, 1274). Refocusing scholarly attention on the relations between racial practices and ideas inverts normal conceptualization of racialism. "This, in short, might better be characterized as the globalization of the racial than as the racialization of the globe" (Goldberg 2009, 1275).

I have only sketched Dikötter's and Goldberg's ideas here in order to illustrate that SC scholars are more than up to the challenge of explaining both the local and the global appearance of racial ideas. Nor are these the only two models available to SC scholars, as this kind of thinking has flourished in the past three decades. In a recent survey of such theories, methods, and studies, Rogers Brubaker argues that "a growing body of work has reframed the study of ethnicity, race, and nationalism in broader and more integrated terms ... that construes ethnicity, race, and nationhood as a single integrated family of forms of cultural understanding, socialization, and political contestation" (Brubaker 2009, 22). The important point for my present argument is Brubaker's conclusion:

The field is global. By global I do not mean that the field covers all world regions, although it does in fact do so. I mean rather that the field is increasingly informed by an understanding of the world as a single integrated social, economic, political, and cultural space. Varying configurations of ethnic, racial, and national classification, social organization, and political claims-making are increasingly understood to have been generated by structural and cultural transformations that have been global in scope, though regionally differentiated in their effects. (Brubaker 2009, 23)

By rejecting the billiard-ball notion of independent cultures, SC theorists can account for racial similarities across the globe. Two points follow. First, when SC theorists find examples of racialism in different places, they do not need to supplement their accounts with psychological accounts about generalizing cognitive mechanisms because such mechanisms are, as Hochman argues, "explanatorily redundant" (Hochman 2013, 1002). To do so would be "as if someone proposed to account for the pattern of motor traffic in London with an explanation of how the internal combustion engine functions" (Bloch 2005, 14). Second, and more fundamentally, the appearance of similar racial ideas across the globe cannot serve as evidence for the 
existence of general psychological mechanism because there are confounding causal variables relating to the diffusion of racial ideas across the globe.

The methods employed by SC researchers who treat the globe as a single culture and those of CEP researchers conducting cross-cultural/comparative research are very different. The process of comparison treats examples as "independent cases that are brought together analytically by asking for similarities and differences between them. In other words, the comparison breaks continuities [and] cuts entanglements" (Kocka 2003, 41). This method is in tension with the notion of "entangled histories" which "is interested in travelling ideas, migrating people, and transnational commerce" (Kocka 2003, 42; see also Kolchin 2009, 579). CEP's program, which treats cultures as independent ontological entities, faces vexing problems. In the next section I will demonstrate these problems.

\section{Galton's Problem: An Unsolved Problem in the GEP Program}

Anthropology was the discipline in which comparative/cross-cultural research was most fully developed, and there were two methods of comparative anthropological research. First are those methods which made a statistical comparison of a large number of cases in which cultural traits were abstracted and fitted into a taxonomy developed for the purposes of such a comparison. George Murdock's Cross-Cultural Survey at Yale's Institute of Human Relations is the most developed and famous example of this approach. Murdock had data on three hundred societies that he placed in seven hundred categories as he sought cross-cultural generalizations. The second approach took a much more limited number of cases and performed a careful and controlled comparison of cultures within a carefully specified region. British structural functionalism was the best example of this approach. Each tradition declined at (least in part) for reasons outlined above: the increasing recognition that modernity and capitalism, and their child imperialism, had interconnected the world in such a way as to frustrate the ambitions of such approaches (Brettell 2009, 651-653). The same problems that frustrated these two research programs remain for any proposed CEP research program that wants to claim evidence from cross-cultural research.

What is important for my present purposes is that the cross-cultural approach of CEP does not seem to fit neatly in either of these traditions: it has not generated enough examples of racialism to make a statistical comparison meaningful. However, its method of seeking out only markers of racialism alone, rather than deep understandings of an entire culture, means it does not really fit the second method either. What I will show in the remainder of this paper is that CEP researchers have thus failed to meet the probative obligations that accompany the kind of claims they are making about the existence of their psychological mechanism.

CEP theorists have a number of cross-cultural examples where they have claimed to have discovered racialism. Lawrence Hirschfeld has pointed to experimental evidence from North America, China, Israel, Ethiopia, and Korea that infants recognize race and prefer their own race. He claims that this literature is "refreshingly global in scope" (Hirschfeld 2012, 18). We can add to his list perhaps a few more nations from the CEP literature, such as Gil-White's study in Mongolia (Gil-White 2001a), but not many more. Nineteenth-century anthropologists would have sneered at this tiny sample size. In what is considered the very first work of comparative anthropology, Edward B. Tylor formulated a theory of the "formation laws of marriage and descent" based on data he had collected from "between three and four hundred peoples, ranging from insignificant savage hordes to great cultured nations" (Tylor 1889, 246). When he presented his paper, the very first question, posed by Francis Galton, deflated his results. "It was extremely desirable for the sake of those who may wish to study the evidence for Dr. Tylor's conclusions," Galton argued, "that full information should be given as to the degree in which the customs of the tribes and races which are compared together are independent" (Tylor 1889, 270). "Galton's problem," as it came to be called, would vex comparative methodologies from that time forward.

Several statistical solutions have been proposed for Galton's problem, but there is no firm consensus as to its solution (Naroll 1961, Strauss et.al. 1975, Ember, Ember and Peregrine 2015). The statistical version of the problem does not (yet) arise for CEP, because they do not have enough examples to make statistical analysis such as these possible. But Galton's problem also involves cultural, not statistical, independence, and this problem does arise for CEP. If cultures are related to each other, then the similarities among them could be explained by cultural rather than psychological causes. In order to make cultural invariance count as evidence for an evolved psychological mechanism, CEP must show that there are cultures without a shared cultural environment, in order to trace the cause back to the Pleistocene.

Even so, as Hochman argued, "we should be wary of easy arguments from the universality of a trait to the existence of an adaptation dedicated to that trait. Just as not everything that has evolved is universal, not 
everything that is universal has evolved" (Hochman 2013, 999). Nor is universality necessarily proof of cultural diffusion from a common source; facts such as dogs making dogs and cats making cats can be learned in different ways. As Hochman concludes, "what science tells the North American students, experience tells the Itzaj [in South America] (Hochman 2013, 999). This too, is an old idea in the human sciences, dating back at least to Franz Boas's dictum that "unlike causes produce like effects" (Boas 1887, 485). "It is of very rare occurrence that the existence of like causes for similar inventions can be proven," Boas argued in 1887; "on the contrary, the development of similar ethnological phenomena from unlike causes is far more probable, and due to the intricacy of the acting causes" (Boas 1887, 485). Put simply, the global distribution of racial thinking carries with it two sets of probative obligations: first, to show that racialism has a common cause at all and, second, to show that diffusionist models cannot explain global racialism. Accepting GEP explanations for psychological mechanisms depends on a demonstration of the "the failure of rival explanations" (Sesardic 2003, 430; also Hochman 2013, 995). In terms of their crosscultural claims, GEP theorists have not met these obligations.

To demonstrate the unmet probative obligations on CEP research, I will examine a recent case made by a CEP philosopher, Ron Mallon's (2013) "Was Race Thinking Invented in the Modern West?" Mallon argues that "lineage essentialism," a key part to racialism, appears in two different cultures and that these cases provide good evidence for the existence of an underlying cognitive mechanism. I will examine each case to show two things: first, that there is no evidence that the cultures, Brazil and Madagascar, are "independent" of European/North American racial traditions.; second, that a more nuanced understanding of the cultures should make us doubt that GEP researchers have understood the "racialism" they have claimed to discovered.

\subsection{Brazil}

Mallon (2013) examines Brazil as an example of how "lineage essentialism is found in representations of human groups independent of the European American tradition of scientific racialism that came to a head in the nineteenth century, supporting an evolutionary cognitive explanation of lineage essentialism about human groups" (83, my emphasis). Mallon argues that SC researchers hold that Brazilian racial categories are, generally, much more fluid than in the United States. Recent experimental evidence, however, such as that supplied by Jones (2009), has shown that Brazilians do think in lineage-essentialist terms. This counts as evidence for the CEP account because "evolutionary cognitive accounts suggest that we ought to expect strong overlap in classification judgments of nonmixed race persons between the United States and Brazil, and this is just what we find. In both countries, a child of two parents of the same race is typically classified as a member of that race (when the parent's race is known)" (Mallon 2013, 85).

\subsubsection{Is Brazil "Independent" of Global Racialism?}

Mallon concludes his discussion of Brazil by noting "While the Brazilian experimental evidence is powerful, it remains consistent with the idea that racial essentialism was introduced in modern Europe and America and somehow imported by Brazil" (Mallon 2013, 85, my emphasis). However, Mallon merely asserts that Brazil is independent of European/North American racial traditions. Even a cursory examination of interconnections between Brazil and such European/North American racial ideologies makes clear that there is no need to speculate that "somehow" racial ideologies appear in Brazil. To begin with, there is reason to think that no importation was necessary. Recent work on the history of racialism has made a good case for relocating its origins from the metropole to the colonies (Anderson 2014, Stoler 1997, Seth 2014). Jorge CañizaresEsguerra has shown that European colonists in Latin America began arguing against theories of environmental determinism in order to fix race in the inherited bodily characteristics of their colonial subjects long before those they left behind in Europe. They did so precisely because they wanted to assure the homeland that there was no danger of the environment turning them into natives (Cañizares-Esguerra 1999, 2006).

Proto-racist ideas were brought from the Portugal to Brazil, where they were hardened because of the ideological necessity of propping up the Atlantic slave trade (Sweet 1997). Far from being independent of lineage essentialism, Latin America was one of its cradles. Historians continue to map a history of an interconnected Atlantic world that traces the origins of racial and ethnic thinking without reifying national boundaries (Sidbury and Cañizares-Esguerra 2011). Comparisons of Brazil and the United States, such as Mallon's, serve "to isolate the two places, overshadowing the constant communication between them and the

\section{易}


mutual construction of their images" (Wade 2004, 358; see also Andrews 1996). There is little need to jump back to the Pleistocene to find a common causal factor in Brazilian and US racialism.

\subsubsection{Has GEP Research Properly Understood "Racialism" in Brazil?}

We have a SC explanation for the differences between the two sets of psychological evidence presented by Mallon. Gil-White (2001b), a key researcher on whom Mallon relies, points out that previous psychological studies had established a "consensus that has emerged from this research is that racial categories in Brazil are fluid (interpersonally, and perhaps also inter-temporally variable), fuzzy (without clear boundaries), and ambiguous (admitting of different, imperfectly overlapping labels)" (Gil-White 2001b, 221). Gil-White argues that improved methodology in the questioning process would uncover that Brazilians do indeed share much more with North American racialism than previously established (though Gil-White has not yet conducted such research). Thus, Gil-White, and Mallon following him, conclude that our conceptions of racial identity are constrained by an underlying cognitive mechanism.

It may be that a more nuanced understanding of Brazilian racial politics could explain the divergence between these two sets of findings. One criticism of Gil-White's (2001a) research on Mongols and Kazakhs is that he does not explain changes in racial attitudes over generations (Rong 2001, Hochman 2013, 1001). In Brazil, Gil-White proposes to explain an intergenerational change in racialism by pointing to improved methodology in psychological testing, but it is not at all clear that such a methodology is needed to explain the intergenerational change. Much of evidence that Gil-White and Mallon are refuting is quite old, much of it flowing from a research program of Marvin Harris from the nineteen-sixties (e.g. Harris and Kottack 1963, Harris 1970). Jones conducted his research, and Gil-White issued his critique, decades later. A constructionist perspective would ask if the social climate surrounding racial issues has changed in the decades between the two sets of results. Psychological studies are not "not separate from the phenomenon they were studying - they were themselves part of it" and, thus, "failure to replicate does not, as in other disciplines, mean that we have to re-examine the original methods and procedures until we have diagnosed a mistake" (Richards 1987, 207; see also Richards 2002, 2012). It may well be that Brazilian racial attitudes changed between the original studies in the nineteen sixties and subsequent studies conducted three decades later.

Both Gil-White and Mallon point to a consensus in the "literature on the cognitive models of race in Brazil" (Gil-White 2001b, 221) that racial beliefs in Brazil are substantially different than in North America. Had they looked to anthropology, history, sociology, or political science, they would have found an opposite consensus. "The debate has moved on somewhat from the question of whether or not racialism exists in Brazil and other Latin American countries," writes anthropologist Peter Wade; "it is unquestionable that it does" (Wade 2004, 357). Studies done in the nineteen-sixties and seventies were conducted during a time when discussions of race were expressly forbidden by the ruling military government (Coates 2007, 324). This policy was consistent with a narrative common in the first half of the twentieth century that presented Brazil as a racial democracy where racial stereotyping barely existed. "Brazilian students of race relations could not but deny race any political significance in the modern Brazilian social configuration ... in the 1950s and 1960s" (da Silva 2004, 720). Researchers working under the spell of modernization theory and funded by UNESCO explained away any counter-evidence that pointed to the existence of racialism by appealing to "the persistence of traditional strongholds in the "yet to be modernized' Brazilian social space," since racist ideology was so prevalent in previous centuries (da Silva 2004, 720). In other words, scholars had no need to jump back to our distant evolutionary past, since the presence of racist ideology was so wellunderstood in Brazil, although believed to be waning under the expected modernization of the country.

Beginning in the nineteen-seventies, there has been much more open communication about the widespread racialism experienced by people of color in Brazil (Andrews 1996, 483; Sousa and Nascimento 2008; Telles and Sue 2009). The earlier ideology in which Brazil was held to be racially different from North America and the discouragement of open discussion of racialism are now seen as "cultural censorship" (Sheriff 2000). Indeed, the ideology of fluid racial categories was used strategically throughout the twentieth century to reinforce rather than undermine racialism, "to see mixture and hybridisation as inherently opposed to racial absolutism and essentialism is quite wrong" (Wade 2004, 356). "The importance of these studies [conducted since the nineteen-seventies] does not reside in any theoretical innovation regarding the workings of racial subjection in Brazil." The importance rests on the notion that modernization will not bring about the end of racialism and in increasing recognition of the reality of racial oppression that is a consequence of Brazil's so-called "fluid" racial categories (da Silva 2004, 720). The kinds of social scientific inquiry done in mid-century Brazil are often now seen as a product of an ideology that incorrectly drew sharp contrasts between the racialism of Brazil and the United States (Agier 1995: Guimarães 1995, 209-211) and that, in 
fact, "a national ideology promoting race mixture and multiracial identification has actually created a situation in which racialism can thrive" (Telles and Sue 2009, 134). So, rather than uncovering evidence of an underlying cognitive mechanism, CEP's experimental evidence could actually be a product of shifting social and cultural patterns of Brazil's racial conditions. This specific case instantiates Hochman's more general argument that it is mistake to separate out racialism from racism because "historically, racism has gone hand in hand with racialism. Furthermore, the negative value judgments associated with racism, and also ethnocentrism, may play a role in essentialist thinking about the 'other"' (Hochman 2013, 1003).

\subsection{Madagascar}

Brazil is not Mallon's only example of racialism. He also points to the appearance of lineage essentialism in Madagascar. Here, Mallon relies on a study conducted by Rita Astuti, an anthropologist with a long history of studying the Vezo, a fishing group on the coast of Madagascar, who worked with Gregg Solomon and Susan Carey, two cognitive developmental psychologists (Astuti, Solomon and Carey 2004). Mallon reports the results of their experiments:

When given an "adopted at birth task" in which Vezo children are raised by Masikoro (an inland group) or Karany (descendants of immigrants to Madagascar from the Indian subcontinent), adult Vezo consistently judge that group identity is fixed by way of life (2004, Study 1, pp. 44ff.), fitting with earlier ethnographic work on Vezo conceptions of Vezo identity. However, 6-13 year old children show an adopted parent bias (the child will have the group identity of the adopting parents) when the switch is Vezo-Masikoro, but a birth parent bias when the switch is Vezo-Karany. (Mallon 2013, 85)

Such evidence, he claims, is "(admittedly prima facie) evidence against both culturally-transmitted theories and culturally-transmitted essentialist construals (for both would predict that the absence of essentialism about human groups is the default)" (Mallon 2013, 85-86).

\subsubsection{Is Madagascar "Independent" of Global Racialism?}

The absence of racialism is not the "default" position of the social constructionist in an interrelated world. Indeed, the constructionist position would seek different modes of transmission for ideas into this region of the world. Madagascar has long been a global crossroads for different groups of people. The island was first settled by people from Indonesia despite the island's proximity to Africa (Adelaar 2009) and the languages on the island are part of the Asian, not African, language groups (Bouwer 2005). For centuries the Malagasy peoples have been trading throughout the Indian Ocean (Crossland 2013, 7-10). Since the nineteenth century, the island has been marked by continual disputes about a national identity, and these disputes continued after the country escaped from French colonial rule in 1960 (Bouwer 2005). In the past twenty-five years, the number of tourists, drawn by the incredible eco-diversity of the island, has quadrupled, despite several political crises that the island has experienced (Walsh 2012, xiii). When surveyed in this long historical context, we find that "the references for collective identities are multiple, heterogeneous and non-exclusive. Madagascar offers a number of examples of this pluri-identity and of the strategically different use that persons and groups can make of it. The different identities are inter-related and inserted in human relations" (Alvarez 1995, 82). Given that the "default" position is not the absence of racialism but its presence, especially in a formerly colonized territory, it is incumbent upon CEP researchers to explain why these potentially confounding causal factors do not throw serious doubt onto their claims about cognitive mechanisms.

The Vezo, the particular people of interest in the research Mallon cites, are not immune to this interconnected world; indeed the areas on the island they occupy have been in contact with Europeans since the sixteenth century (Marikandia 2001, 158). The Vezo's traditional fishing lifestyle means they are in constant negotiations with neighbors about fishing rights and boundaries, marking off where they may fish and where they may not. Their fishing lifestyles are entwined with national and global economies (Iida 2009; Tucker et. al. 2011, 294). The particular community studied by Astuti, on whom Mallon relies, is not cut off from the rest of the world and, indeed, lies in close proximity to a town with an airport, post office, and market. Moreover, it has become a very busy tourist attraction in the past thirty years (Astuti, et. al. 2004, 18). On a more local level, the intermarriage of Vezo with the Masikoro, their agricultural and pastoral neighbors is common (Dina 2001; Tucker et. al. 2011).

\section{易}




\subsubsection{Has GEP Research Properly Understood "Racialism" in Madagascar?}

Ideas of lineage essentialism are indeed present among the Vezo, for example, to explore the difference between Vezo vatane (who live by the sea and fish) and the Vezo-potake (who have moved to the village or city and do not fish). What Mallon calls "lineage essentialism" is certainly present in these questions for the Vezo: how can "a potential successor of a patriarchal ritual clan or lineage pole holder who has converted to Christianity and who refuses the cult of ancestors, be considered a 'true Vezo'? Similarly, how could an urban Vezo, visiting the village and not even sitting on the ground, while all the elders are found there, go back to being a true Vezo again?" (Marikandia 2001, 158-9).

It would be incorrect then for a CEP researcher to claim, as Mallon does, that "Vezo consistently judge that group identity is fixed by way of life" (Mallon 2013, 85, my emphasis); indeed such a claim cuts against Astuti's close analysis of how the Vezo conceptualize identity. Her argument is that identity is never "fixed;" rather it is a process that needs to be continually made and remade. "Vezo adults know that their babies get their physiognomy from their birth parents, but choose to state otherwise," she writes (Astuti 2007, 14). The cultural significance of their claim rests on the importance that parents in Vezo communities do not have exclusive rights to their children, the children are the responsibility of everyone in the village (Astuti 1995, 2007). Astuti's position is a good example of what Hochman (2013) called the "wealth of stimulus" argument: the Vezo know that their children resemble their parents, because the evidence of their eyes tells them so. As Hochman noted, "nativist theories are only compelling when learning cannot account for the relevant data. However, the fact that cats beget cats, and dogs beget dogs, and that they somehow transmit catlike natures and doglike natures, is not ecologically opaque" (Hochman 2013, 999). And neither, I would argue, is the fact that children physically resemble their parents. What seems much more interesting is that the Vezo are taught to also claim that children resemble those to whom they are not biologically related. This is because their social/cultural goals are to expand kinship relations far beyond the biological parents. "While this objective is inherent to the Vezo undifferentiated system of kinship reckoning, which is inclusive rather than exclusive," Astuti concludes, "people also actively pursue this end in their everyday practices" (Astuti 2007, 10). There is good reason to doubt that the complexity of racialism among the Vezo is adequately captured by the kind of psychological experiments relied on by Mallon.

Even if we grant that the psychological experiments described by Mallon have found some underlying racialism, have they discovered the same thing that was discovered in Brazil and is so prevalent in the United States and Europe? As Astuti noted, "comparison requires commensurability" (Astuti et. al. 2004, 12). In what sense is the community of Vezo commensurable with other examples CEP researchers rely on? Like Galton's problem, this question dates back to 1889, when Dr. Flower raised a second objection to Tyler's work: "It was, however, perfectly obvious that the value of such a method depended entirely upon the units of comparison being of equivalent value, and this seemed to him to be a very great difficulty when dealing with groups of mankind" (Tyler 1889, 271). "Flower's question," as it came to be known (Korotayev and de Munck 2003), involves a question of scale. Mallon (2013) has two examples of inheritance thinking: Brazil and the Vezo. Are these two equivalent examples? Brazil is a huge, industrializing, multi-ethnic country. The Vezo are small groups on the coast of Madagascar. Do we count the Vezo vatane as separate from or the same as the Vezom-potake? In what sense, exactly, does an enormous industrial culture like Brazil have similarities or differences to a small group in Madagascar? "It may be that the differences between industrial and foraging cultures," concludes one comparativist anthropologist, "are so vast and complex that for some questions it would be hard, if not impossible, to find items that have a comparable functional niche" (de Munck 2000, 280; see also Gatewood 2000). Flower's question, even when not called that, is an ongoing research program among those struggling to describe the tensions between global and local, between particular communities and vast capitalist transnational systems (Swyngedouw 2004). In a review of the studies searching for essentialism, Heinrich and his colleagues find that the "evidence is not well suited to examining differences in the degree of psychological essentialism across populations" (Henrich, Heine and Norenzayan 2010, 69), because of the vast different social structures of the societies under examination.

\section{Gonclusion}

The cross-cultural evidence for the existence of a species-typical cognitive mechanism that accounts for racialism faces significant problems that CEP researchers need to address. Moreover, the methods of cognitive psychology are hardly uniform in their findings. More recent studies have been much more equivocal in their findings about the very areas of the world that I have examined here: Latin America and Madagascar. Denis Regnier found that, among other ethnicities in Madagascar, lineage essentialism did not 
arise until the colonial period on the island, just as SC research would predict. Regnier's psychological experiments to uncover the source of racialism could not be interpreted to show the existence of a cognitive model that accounts for it (Regnier 2015). More recent research fails to find evidence of any underlying cognitive mechanism for racialism. Tamara Hale's psychological experiments among the Yapatera of Peru showed their cognitive processes were in line with their non-essentialist ideology of race:

The results of the experimental studies confirm the ethnographic account of the folk theory of race that villagers in Yapatera articulate in their everyday lives and interactions. Despite their exposure to essentialist constructions of race, villagers used their non-essentialist folk theory to inform their reasoning in the tasks. (Hale 2015, 148)

Such research should continue in the future, but it must be done in closer conversation with the methods and theories of social constructionist research. I agree with the plea of CEP researchers that the evolutionary cognitive researchers and social constructivist researchers need to be in closer communication. However, rather than faulting SC researchers for neglecting CEP approaches, I argue that the opposite is a much greater problem. CEP researchers make claims about "independent" cultures without coming to grips with the probative obligations that are concomitant with such a claim. These obligations, I should stress, have been well understood for over a century. I agree with two anthropologists who are sympathetic to GEP approaches when they find that "behavioral scientists should pay more attention to the work of cultural/social anthropologists, since these are the scientists who have made human variability their main focus," because "the solution cannot be ... to administer studies upon studies to the billions of (poor) people around the world who remain untapped by the behavioral sciences" (Astuti and Bloch 2010, 84). Rather, it requires researchers to be sensitive to the complexity of human culture and cognition - a sensitivity that can only arise from a true collaboration between evolutionary/cognitive psychologists and those working in anthropology, history, and sociology.

\section{Notes}

1. Appiah distinguishes "racialism" which is the belief that races can be distinguished from each other from "racism" which adds value judgments to establish racial hierarchies. Machery and Faucher (2005a, 1208) follow this line as well. Hochman (2013) critiques the distinction on the basis that racialism cannot be so easily separated from racism as value judgments may be constitutive of racialism itself. I agree with Hochman and return to this point in section 5.1.2 of the present paper.

2. Bloch does suggest that diffusionist explanations are overused in the social sciences, however.

\section{Literature cited}

Adelaar, A. 2009. Towards and integrated theory about the Indonesian migrations to Madagascar. In Ancient human migrations: a multidisciplinary approach, edited by PN Peregrine, I Peiros, and M Feldman. Salt Lake City: University of Utah Press.

Agier, M. 1995. Racism, Culture and Black Identity in Brazil. Bulletin of Latin American Research 14 (3): 245-264. doi:10.1111/j.1470-9856.1995.tb00010.x.

Alvarez, AR. 1995. Ethnicity and Nation in Madagascar. In Cultures of Madagascar: Ebb and Flow of Influences, edited by S Evers and M Spindler. Leiden: International Institute for Asian Studies.

Anderson, W. 2014. Racial Conceptions in the Global South. Isis 105 (4): 782-792. doi:10.1086/679425.

Andrews, GR. 1996. Brazilian Racial Democracy, 1900-90: An American Counterpoint. Journal of Contemporary History 31 (3): 483-507. doi:10.1177/002200949603100303.

Appiah, A. 1990. Racisms. In Anatomy of Racism, edited by DT Goldberg. Minneapolis: University of Minnesota Press.

Astuti, R. 1995. People of the Sea: Identity and Descent among the Vezo of Madagascar. Cambridge

University Press, March.

- 2007. Weaving Together Culture and Cognition: An Illustration from Madagascar. Intellectica:

Revue de L'association Pour la Recherche Cognitive 46/47: 173-189. doi:10.3389/fpsyg. 2015.00136.

Astuti, R, and M Bloch. 2010. Why a Theory of Human Nature Cannot Be Based on the Distinction 
Between Universality and Variability: Lessons from Anthropology. Behavioral and Brain Sciences 33 (23): 83-84. doi:10.1017/S0140525X10000026.

Astuti, R, GEA Solomon, and S Carey. 2004. Constraints on Conceptual Development: A Case Study of the Acquisition of Folkbiological and Folksociological Knowledge in Madagascar. Monographs of the Society for Research in Child Development 69 (3): i-135. doi:10.1111/j.0037-976x.2004.00302.x.

Banton, M. 1970. The Concept of Racism. In Race and Racialism, edited by S Zubaida. London: Tavistock. Berg, M, and S Wendt. 2011 a. Introduction: Racism in the Modern World: Historical Perspectives on Cultural Transfer and Adaptation. In Racism in the Modern World: Historical Perspectives on Cultural Transfer and Adaptation, edited by M Berg and S Wendt. New York: Berghahn Books.

Berg, M, and S Wendt, eds. 2011 b. Racism in the Modern World: Historical Perspectives on Cultural Transfer and Adaptation. New York: Berghahn Books.

Bloch, M. 2005. Essays on Cultural Transmission. Oxford: Berg Publishers.

Boas, F. 1887. The Occurrence of Similar Inventions in Areas Widely Apart. Science 9 (May): 485-486. doi:10.1126/science.ns-9.224.485.

- 1896. The Limitations of the Comparative Method of Anthropology. Science 4 (103): 901-908. doi:10.1126/science.4.103.901.

Bonilla-Silva, E. 2014. Racism Without Racists: Color-Blind Racism and the Persistence of Racial Inequality in America. Fourth edition. Lanham: Rowman \& Littlefield Publishers, Inc.

Bouwer, L. 2005. Towards a Sociolinguistic Profile of Madagascar: Issues of Diversity. Language Matters 36 (1): 98-116. doi:10.1080/10228190508566237.

Brettell, CB. 2009. Anthropology, Migration, and Comparative Consciousness. New Literary History 40 (3): 649-671. doi:10.1353/nlh.0.0107.

Brubaker, R. 2009. Ethnicity, Race, and Nationalism. Annual Review of Sociology 35: 21-42. doi:10.1146/annurevsoc-070308-115916.

Caizares-Esguerra, J. 1999. New World, New Stars: Patriotic Astrology and the Invention of Indian and Creole Bodies in Colonial Spanish America, 1600-1650. The American Historical Review 104 (1): 3368. doi:10.2307/2650180.

- 2006. Nature, Empire, and Nation: Explorations of the History of Science in the Iberian World. Stanford, Calif: Stanford University Press.

Coates, RD. 2007. Racial Hegemony, Globalization, Social Justice, and Anti-Hegemonic Movements. In Handbooks of the Sociology of Racial and Ethnic Relations, edited by H Vera and JR Feagin, 319-342. New York: Springer.

Crossland, Z. 2013. Ancestral Encounters in Highland Madagascar. New York: Cambridge University Press. Da Silva, DF. 2004. An Introduction: The Predicament of Brazilian Culture. Social Identities 10 (6): $719-$ 734. doi:10.1080/1350463042000323950.

de Munck, V. 2000. Introduction: Units for Describing and Analyzing Culture and Society. Ethnology 39 (4): 279-292. doi:10.2307/3774047.

de Sousa, LC, and P Nascimento. 2008. Brazilian National Identity at a Crossroads: The Myth of Racial Democracy and the Development of Black Identity. International Journal of Politics, Culture, and Society 19 (3/4): 129-143. doi:10.1007/s10767-008-9023y.

Diktter, F. 2008. The racialization of the globe: an interactive interpretation [in Undetermined]. Ethnic and racial studies 31 (8): 1478-1496. doi:10.1080/01419870802208388.

Dina, J. 2001. The Hazomanga Among the Masikoro of Southwest Madagascar: Identity and History. Ethnohistory 48 (1/2): 13-30. doi:10.1215/00141801-48-1-2-13.

Duster, T. 2006. Comparative Perspectives and Competing Explanations: Taking on the Newly Configured Reductionist Challenge to Sociology. American Sociological Review 71 (1): 1-15. doi:10.1177/000312240607100101. 
Ember, CR, M Ember, and P Peregrine. 2015. Cross-Cultural Research. In Handbook of Methods in Cultural Anthropology, edited by HR Bernard and CC Gravlee. Lanham: Rowman and Littlefield.

Ember, M. 1991. The Logic of Comparative Research. Cross-Cultural Research 25 (1-4): 143-153. doi:10. $1177 / 106939719102500106$.

Fredrickson, GM. 1971. Black Image in the White Mind: The Debate Over Afro-American Character and Destiny, 1817-1914. New York: Harper and Row.

- 1981. White Supremacy: A Comparative Study in American and South African History. New York: Oxford University Press.

Fredrickson, GM. 1988. The Arrogance of Race: Historical Perspectives on Slavery, Racism, and Social Inequality. Middletown, Conn.: Wesleyan University Press.

Fredrickson, GM. 1995. Black Liberation: A Comparative History of Black Ideologies in the United States and South Africa. New York: Oxford University Press.

. 1997. The Comparative Imagination: On the History of Racism, Nationalism, and Social Movements. Berkeley: University of California Press.

- 2002. Racism: A Short History. Princeton NJ: Princeton University Press.

Gatewood, JB. 2000. Distributional Instability and the Units of Culture. Ethnology 39 (4): 293-303. doi: $10.2307 / 3774048$.

Gelman, SA. 2003. The Essential Child: Origins of Essentialism in Everyday Thought. Oxford University Press, January.

. 2009. Essentialist Reasoning about the Biological World. In Neurobiology of Umwelt, edited by A Berthoz and Y Christen. Springer Berlin Heidelberg.

Gelman, SA, and LA Hirschfeld. 1999. How Biological Is Esentialism? In Folkbiology, edited by DL Medin and S Atran. Cambridge: MIT Press.

Gil-White, FJ. 2001a. Are Ethnic Groups Biological Species to the Human Brain?: Essentialism in Our Cognition of Some Social Categories. Current Anthropology 42 (4): 515-553. doi:10.1086/321802.

- 2001b. Sorting Is Not Categorization: A Critique of the Claim That Brazilians Have Fuzzy Racial Categories. Journal of Cognition and Culture 1 (3): 219-249. doi:10.1163/156853701753254387.

Goldberg, DT. 2009. Racial Comparisons, Relational Racisms: Some Thoughts on Method. Ethnic and Racial Studies 32 (7): 1271-1282. doi:10.1080/01419870902999233.

Guillaumin, C. 1980. The Idea of Race and Its Elevation to Autonomous Scientific and Legal Status. In Sociological Theories: Race and Colonialism. Edited by UNESCO, vol. 37. Paris: UNESCO.

Guimares, ASA. 1995. Racism and Anti-Racism in Brazil: A Postmodern Perspective. In Racism and AntiRacism in World Perspective, edited by BP Bowser. Thousand Oaks: Sage Publications.

Hacking, I. 1999. The Social Construction of What? Cambridge, Mass.: Harvard University Press.

Hale, T. 2015. A non-essentialist theory of race: the case of an Afro-indigenous village in northern Peru: A

Non-Essentialist Theory of Race. Social Anthropology 23 (2): 135-151. doi:10. 1111/1469-8676.12123.

Harris, M. 1970. Referential Ambiguity in the Calculus of Brazilian Racial Identity. Southwestern Journal of Anthropology: 1-14. doi:10.1086/soutjanth.26.1.3629265.

Harris, M, and C Kottak. 1963. The Structural Significance of Brazilian Racial Categories. Sociologia 25 (3): 203-208. doi:10.1525/aa.2003.105.3.685.

Hecht, JM. 1999. The Solvency of Metaphysics: The Debate Over Racial Science and Moral Philosophy in France, 1890-1919. Isis 90:1-24. doi:10.2307/4613739.

Hecht, JM. 2000. Vacher De Lapouge and the Rise of Nazi Science. Journal of the History of Ideas 61:285304. doi:10.1353/jhi.2000.0018.

Henrich, J, SJ Heine, and A Norenzayan. 2010. The Weirdest People in the World? Behavioral and Brain Sciences 33 (2-3): 61-83. doi:10.1017/S0140525X0999152X.

Hirschfeld, LA. 1994. The Child's Representation of Human Groups. The psychology of learning and 
motivation: Advances in research and theory 31:133-185. doi:10.1016/s0079-7421(08)60410-7.

. 1995. The Inheritability of Identity: Children's Understanding of the Cultural Biology of Race.

Child Development 66 (5): 1418-1437. doi:10.1111/j.1467-8624.1995. tb00943.x.

— 2002. Why Don’t Anthropologists Like Children? American Anthropologist 104 (2): 611-627. doi:10. 1525/aa.2002.104.2.611.

. 2012. Seven Myths of Race and the Young Child. Du Bois Review 9 (1): 17-39. doi:10.1017/S1742058X12000033.

Hochman, A. 2013. Do We Need a Device to Acquire Ethnic Concepts? Philosophy of Science 80 (5): $994-$ 1005. doi:10.1086/673896.

Jackson, WA. 1990. Gunnar Myrdal and America’s Conscience: Social Engineering and Racial Liberalism, 1938-1987. Chapel Hill: University of North Carolina Press.

Jones, D. 2009. Looks and Living Kinds: Varieties of Racial Cognition in Bahia, Brazil. Journal of Cognition and Culture 9 (3): 247-269. doi:10.1163/156770909X12489459066309.

Kelly, D, L Faucher, and E Machery. 2010. Getting Rid of Racism: Assessing Three Proposals in Light of Psychological Evidence. Journal of Social Philosophy 41 (3): 293-322. doi:10. 1111 /j.14679833.2010.01495.x.

Kelly, D, E Machery, and R Mallon. 2010. Race and Racial Cognition. In The Moral Psychology Handbook, edited by JM Doris and MPR Group. Oxford: Oxford University Press.

Kocka, J. 2003. Comparison and Beyond. History and Theory 42 (1): 39-44. doi:10.1111/1468-2303.00228.

Kolchin, P. 2009. The South and the World. The Journal of Southern History 75 (3): 565-580. doi:10.1353/cwh. 1982.0047.

Korotayev, A, and V de Munck. 2003. "Galton's Asset" and "Flower's Problem": Cultural Networks and Cultural Units in Cross-Cultural Research: (Or, Male Genital Mutilations and Polygyny in CrossCultural Perspective). American Anthropologist 105 (2): 353-358. doi:10.1002/9780471740360.ebs0500.

Kühl, S. 1994. The Nazi Connection: Eugenics, American Racism, and German National Socialism. New York: Oxford University Press.

Kurzban, R, J Tooby, and L Cosmides. 2001. Can race be erased? Coalitional computation and social categorization. Proceedings of the National Academy of Sciences 98 (26): 15387-15392. doi:10.1073/pnas. 251541498 .

Lowie, RH. 1936. Cultural Anthropology: A Science. American Journal of Sociology 42 (3): 301-320. doi:10.4135/9781452276311.n163.

Machery, E, and K Cohen. 2012. An Evidence-Based Study of the Evolutionary Behavioral Sciences. The British Journal for the Philosophy of Science 63 (1): 177-226. doi:10.1093/bjps/axr029.

Machery, E, and L Faucher. 2005a. Social Construction and the Concept of Race. Philosophy of Science 72 (5): 1208-1219. doi:10.1086/508966.

- 2005b. Why Do We Think Racially? edited by H Cohen and C Lefebvre. Amsterdam: Elsevier.

Machery, E, L Faucher, and DR Kelly. 2010. On the Alleged Inadequacies of Psychological Explanations of Racism. Monist 93 (2): 228-254. doi:10.5840/monist201093214.

Malik, K. 1996. The Meaning of Race: Race, History and Culture in Western Society. New York: New York University Press.

Mallon, R. 2010. Sources of Racialism. Journal of Social Philosophy 41 (3): 272-292. doi:10.1111/j.14679833.2010.01498.x.

- 2013. Was Race Thinking Invented in the Modern West? Studies in History and Philosophy of Science 44 (1): 77-88. doi:10.1016/j. shpsa.2012.10.001.

Mallon, R, and D Kelly. 2012. Making Race Out of Nothing: Psychologically Constrained Social Roles. In Oxford Handbook of Philosophy of Social Science. New York: Oxford University Press. 
Mallon, R, and SP Stich. 2000. The Odd Couple: The Compatibility of Social Construction and Evolutionary Psychology. Philosophy of Science 67 (1): 133-154. doi:10.1093/acprof:osobl/9780199734108.003. 0013.

Mallon, R, and JM Weinberg. 2006. Innateness as Closed Process Invariance. Philosophy of Science 73 (3): 323-344. doi:10.1086/515414.

Marikandia, M. 2001. The Vezo of the Fiherea Coast, Southwest Madagascar: Yesterday and Today. Ethnohistory 48(1/2): 157-170. doi:10.1215/00141801-48-1-2-157.

Mill, JS. 2008 [1851]. A System of Logic, Ratiocinative And Inductive (Vol. 1 of 2).

Naroll, R. 1961. Two Solutions to Galton's Problem. Philosophy of Science 28 (1): 15-39. doi:10.1525/aa.1963.65. 5.02a00050.

Omi, M, and H Winant. 2002. Racial Formation. In Race Critical Theories, edited by P Essed and DT Goldberg. London: Blackwell.

Orellana, MF, and B Thorne. 1997. Race in the Making: Cognition, Culture, and the Child's Construction of Human Kinds by Lawrence A. Hirschfeld. American Journal of Sociology 103 (2): 501-503. doi: $10.1086 / 231234$.

Regnier, D. 2015. Clean people, unclean people: the essentialisation of slaves among the southern Betsileo of Madagascar. Social Anthropology 23 (2): 152-168. doi:10.1111/14698676.12107.

Richards, G. 1987. of What Is History of Psychology a History. British Journal for the History of Science 20 (65): 201-211. doi:10.1017/s0007087400023748.

. 2002. Putting Psychology in Its Place: A Critical Historical Overview. 2 ed. New York: Routledge. 2012. 'Race', Racism and Psychology: Towards a Reflexive History. London: Routledge.

Rong, M. 2001. Comment on 'Are Ethnic Groups Biological Species to the Human Brain?' Current Anthropology 42:543-544. doi:10.1086/321802.

Sesardic, N. 2003. Evolution of Human Jealousy A Just-So Story or a Just-So Criticism?. Philosophy of the Social Sciences 33 (4): 427-443. doi:10.1177/0048393103257964.

Seth, S. 2014. Introduction: Relocating Race. Isis 105 (4): 759-763. doi:10.1086/679422.

Sheriff, RE. 2000. Exposing Silence as Cultural Censorship: A Brazilian Case. American Anthropologist 102 (1): 114-132. doi:10.1525/aa.2000.102.1.114.

Sidbury, J, and J Caizares-Esguerra. 2011. Mapping Ethnogenesis in the Early Modern Atlantic. The William and Mary Quarterly 68 (2): 181-208. doi:10.5309/willmaryquar.68.2.0181.

Steinberg, S. 1995. Turning Back: The Retreat From Racial Justice in American Thought and Policy. Boston: Beacon Press.

- 2007. Race Relations: A Critique. Stanford, Calif.: Stanford Social Sciences.

Stoler, AL. 1997. Racial Histories and Their Regimes of Truth. Political Power and Social Theory 11:183206. doi:10.1215/9780822377719-004.

Strauss, DJ, M Orans, JA Barnes, RP Chaney, J De Leeuwe, M Ember, L Greebaum, et al. 1975. Mighty Sifts: A Critical Appraisal of Solutions to Galton's Problem and a Partial Solution [And Comments and Replies]. Current Anthropology 16 (4): 573-594. doi:10.1086/201620.

Sweet, JH. 1997. The Iberian Roots of American Racist Thought. William and Mary Quarterly 54:143-166. doi: $10.2307 / 2953315$.

Swyngedouw, E. 2004. Globalisation or Glocalisation? Networks, Territories and Rescaling. Cambridge Review of International Affairs 17 (1): 25-48. doi:10.1080/0955757042000203632.

Telles, EE, and CA Sue. 2009. Race Mixture: Boundary Crossing in Comparative Perspective. Annual Review of Sociology 35 (January): 129-146. doi:10.1146/annurev.soc.34.040507.134657.

Tucker, B, A Huff, J Tombo, P Hajasoa, C Nagnisaha, et al. 2011. When the Wealthy Are Poor: Poverty Explanations and Local Perspectives in Southwestern Madagascar. American Anthropologist 113 (2): 291-305. doi:10.1111/j.1548-1433.2011.01331.x. 
Tylor, EB. 1889. On a Method of Investigating the Development of Institutions; Applied to Laws of Marriage and Descent. The Journal of the Anthropological Institute of Great Britain and Ireland 18 (January): 245-272. doi:10.2307/2842423.

Verkuytel, M, and J Ter Wal. 2000. Introduction: Racism in a Comparative Perspective. In Comparative Perspectives on Racism, edited by J Ter Wal and M Verkuytel. Aldershot: Ashgate.

Wacquant, L. 1997. For an Analytic of Racial Domination. Political power and social theory 11 (1): 221234. doi:10.1080/01419870.2014.931991.

Wade, P. 2004. Images of Latin American Mestizaje and the Politics of Comparison. Bulletin of Latin American Research 23 (3): 355-366. doi:10.1111/j.0261-3050.2004.00113.x.

Walsh, A. 2012. Made in Madagascar: Sapphires, Ecotourism, and the Global Bazaar. Toronto: University of Toronto Press.

Wellman, D. 2007. Unconscious Racism, Social Cognition Theory, and the Legal Intent Doctrine: The Neuron Fires Next Time. In Handbook of the Sociology of Racial and Ethnic Relations, edited by H Vera and JR Feagin. New York: Springer.

Wolf, ER. 2010. Europe and the People Without History. Berkeley, Calif.; London: University of California Press.

\section{AGKNOWLEDGEMENTS}

Early versions of this paper were read and critiqued by Matthew Kopec, Mark Largent, and Tamara Hale. Any remaining errors are my own.

Copyright (C) 2016 Author(s).

This is an open-access article distributed under the terms of the Creative Commons AttributionNonCommercial-NoDerivs license, which permits anyone to download, copy, distribute, or display the full text without asking for permission, provided that the creator(s) are given full credit, no derivative works are created, and the work is not used for commercial purposes.

ISSN 1949-0739 